\section{Stress hormone}

\section{masculinizes female} morphology and behaviour

\section{Rosemary Knapp ${ }^{1, *, \dagger}$, Edie Marsh-Matthews ${ }^{1,2, \dagger,}$ Luanne Vo ${ }^{1}$ and Sarah Rosencrans ${ }^{1}$}

${ }^{1}$ Department of Zoology, and ${ }^{2}$ Sam Noble Oklahoma Museum of Natural History, University of Oklahoma, Norman, OK 73019, USA

*Author for correspondence (rknapp@ou.edu).

These authors contributed equally to this work.

Sex steroids play major roles in vertebrate sexual differentiation. Unexpectedly, we now find that exposure to elevated levels of the naturally occurring stress hormone cortisol can also masculinize sexually dimorphic morphological characters and behaviour in adult female mosquitofish (Gambusia affinis) in a dose-dependent manner. Females masculinized by cortisol developed elongated anal fins with distal tip features similar to those of mature males. Most masculinized females also attempted to copulate when placed with normal females. Although the mechanism of masculinization is currently unknown, we propose a role for an enzyme that both inactivates cortisol and catalyzes the final step in synthesis of a major teleost androgen. This mechanism may also help explain some previously reported effects of stress on sexual development across vertebrate taxa. Our findings underscore the need to understand the full range of chemicals, both naturally occurring hormones and humanproduced endocrine disruptors, that can influence sexual differentiation and reproductive function.

Keywords: cortisol; masculinization; mosquitofish; stress; endocrine disruptors

\section{INTRODUCTION}

The stress hormones cortisol and corticosterone have numerous, well-documented effects on physiology, reproduction and behaviour in vertebrates [1]. Because glucocorticoids can affect fat deposition in teleost fishes [2], we investigated the use of cortisol for manipulating fat stores of adult female western mosquitofish (Gambusia affinis) as part of ongoing research on resource-dependent maternal provisioning in live-bearing fishes [3]. Although understanding female life history was the impetus for our study, those results will be reported elsewhere. Here, we report a completely unanticipated result of exposure to exogenous cortisol: masculinization in adult females of anal fin morphology and mating behaviour.

Like other poeciliids, $G$. affinis is sexually dimorphic (figure $1 a, c$ ), with adult males possessing a modified anal fin (gonopodium) used for sperm transfer. The gonopodium normally develops under the influence of androgens, and involves elongation of anal fin rays 3, 4 and 5 and development of distal tip structures (hooks,

Electronic supplementary material is available at http://dx.doi.org/ $10.1098 / \mathrm{rsbl} .2010 .0514$ or via http://rsbl.royalsocietypublishing.org. serrae, spines and blades) thereon. Although the anal fin of females is normally unspecialized (figure $1 a$ ), development of gonopodial structures can be induced by exposure to various androgens [4] and endocrine-disrupting chemicals (EDCs) such as those found in effluent from paper mills [5]. Indeed, the sensitivity of female mosquitofish morphology and behaviour to androgenic EDCs has lead to this species' use as sentinels for such environmental contamination [5]. Although exposure to stress or to natural and human-produced androgenic and oestrogenic compounds early in life affects morphology and behaviour in both sexes across vertebrate taxa $[6,7]$, stress hormones such as cortisol have not been previously shown to induce masculinization of reproductive morphology or behaviour in mature individuals. However, there are intriguing reports of early exposure to elevated levels of glucocorticoids inducing altered offspring sex ratios (e.g. $[8,9]$ ).

\section{MATERIAL AND METHODS}

We conducted two experiments: the initial pilot study in which we discovered the masculinizing effect of cortisol and a follow-up study to examine behaviour and effects of lower cortisol dosages. For both experiments, gravid female western mosquitofish (judged by the presence of a gravid spot and distended abdomen) were collected on the University of Oklahoma campus. Females were taken to a greenhouse and placed individually in 1.21 plastic (PETE) containers containing 11 charcoal-filtered well water. Fish were fed approximately $50 \mathrm{mg}$ of commercial flake food every other day.

On the day that a female gave birth (day 1), she was moved to a clean container and randomly assigned to one of five treatment groups. A male was placed with her on days 2 and 3 to ensure fertilization of the subsequent brood. On day 3 (after male was removed), treatment began with $1 \mathrm{ml}$ of cortisol, ethanol (vehicle) or charcoal-filtered well water added directly to the container water and continued every 3 days for the duration of the experiment. In experiment 1 , cortisol treatments were $0.5,1.0$ or $2.0 \mathrm{mg} \mathrm{l}^{-1}$, and in experiment 2 they were $0.05,0.1$ or $0.5 \mathrm{mg} \mathrm{l}^{-1}$. Water was changed every 6 days (without handling the female). At the end of the experiment, females were euthanized by an overdose of MS-222 and preserved in 10 per cent unbuffered formalin; see electronic supplementary material, $\mathrm{S} 1$, for additional detail.

Anal fins were removed from preserved females, examined under an Olympus SZX12 stereomicroscope using transmitted light and photographed at $7 \times$ magnification with an Olympus Spot Idea camera. The lengths of bony fin rays 4 and 6 were measured to the nearest $0.1 \mathrm{~mm}$ as the straight-line distance from the attachment of the bony fin ray to the pterygiophore of the fin suspensorium to the distal extent of the ray, using ADVANCED SPOT software (figure $1 d$ ). The ratio of lengths of ray 4 to ray 6 was used as an index of the degree of masculinization [10], hereafter referred to as the masculinization index (MI), with higher values indicating greater elongation of ray 4 and greater masculinization (electronic supplementary material, $\mathrm{S} 1$ ).

Behavioural tests were conducted with fish from experiment 2. One set of tests focused on the behaviour of experimental females towards a stimulus female, and another set focused on the behaviour of males towards the experimental females. For the female trials, an experimental female ( $n=5-12$ per treatment group) was placed in a 17.61 glass aquarium with a stimulus female from the same population who had also been isolated for at least 2 days prior to the trial. After acclimation for $10 \mathrm{~min}$, behaviour of the experimental female towards the stimulus female was observed for $10 \mathrm{~min}$ and scored for number of copulation attempts. All female trials were recorded by L.V. who was blind to the female's treatment group. For the male trials, R.K. (also blind to the female's treatment) scored the number of male copulation attempts towards experimental females (electronic supplementary material, S1).

Non-parametric Kruskal-Wallis tests (PASW v. 18) were used to compare MI and copulation attempts among treatments. Because water and ethanol control groups did not differ significantly for female copulatory behaviour, these groups were combined for the statistical analysis of behavioural results.

\section{RESULTS}

In both studies, anal fins of cortisol-exposed females, but not control females, became masculinized in a dose-dependent manner (figures $1 b, 2 a$ ). The MI for 


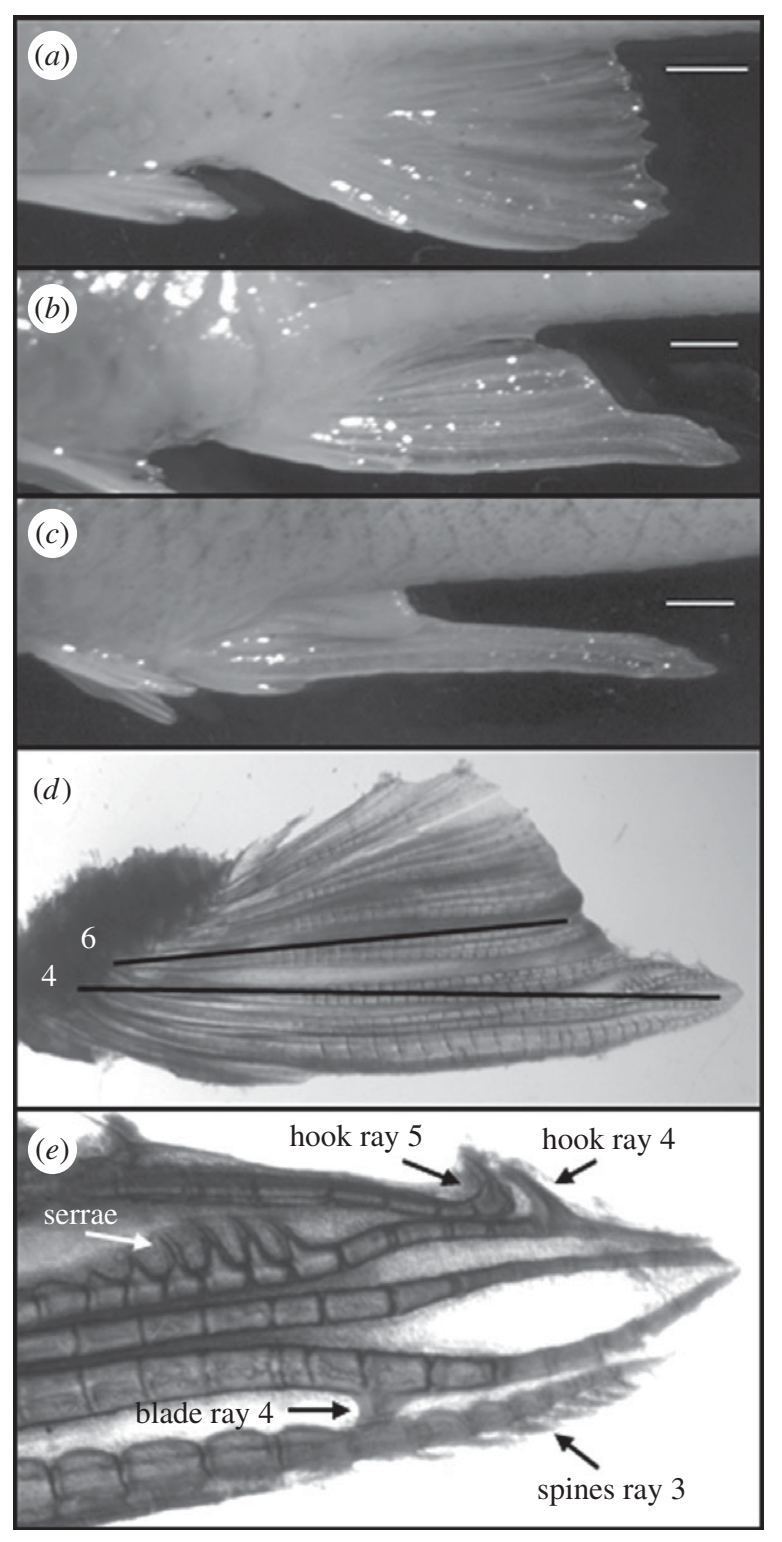

Figure 1. Cortisol-induced masculinization of adult female mosquitofish. Anal fins of $(a)$ normal female, $(b)$ cortisolexposed female and (c) normal male. (d) Anal fin of a cortisol-treated female illustrating ray length measurements (black lines) used to calculate the masculinization index (see text). (e) Distal tip structures on the anal fin of a cortisol-treated female (alizarin stain). Scale bars, $(a-c) 1 \mathrm{~mm}$.

all females in both experiments ranged from 1.02 to $1.61(n=124)$, with a range of $1.12-1.61$ for females that developed male-typical distal tip structures $(n=$ 51). The MI varied significantly among treatments in experiment $1 \quad\left(n=72, \quad \chi^{2}=46.79, \quad\right.$ d.f. $=4, \quad p<$ $0.0001)$ and in experiment $2\left(n=53, \chi^{2}=26.16\right.$, d.f. $=4, p<0.0001$ ), with the highest MI from females exposed to $0.5 \mathrm{mg} \mathrm{l}^{-1}$ in both cases (figure $2 a$ ). Combined responses for the two experiments suggest an overall inverted U-shaped response curve.

In experiment 1,39 of 46 females $(84.8 \%)$ exposed to cortisol $\left(0.5 \mathrm{mg} \mathrm{l}^{-1}\right.$ : 12 of $13 ; 1 \mathrm{mg} \mathrm{l}^{-1}$ : 12 of 16 ; $2 \mathrm{mg}^{-1}$ : 17 of 17) developed distal tip structures on bony fin rays $3-5$, while none of the 33 females exposed to control treatments (18 water; $15 \mathrm{EtOH}$ ) developed such structures. In experiment 2,16 of 24 females $(66.7 \%)$ exposed to $0.5 \mathrm{mg}^{-1}$ cortisol developed distal tip structures, but no females exposed to either control
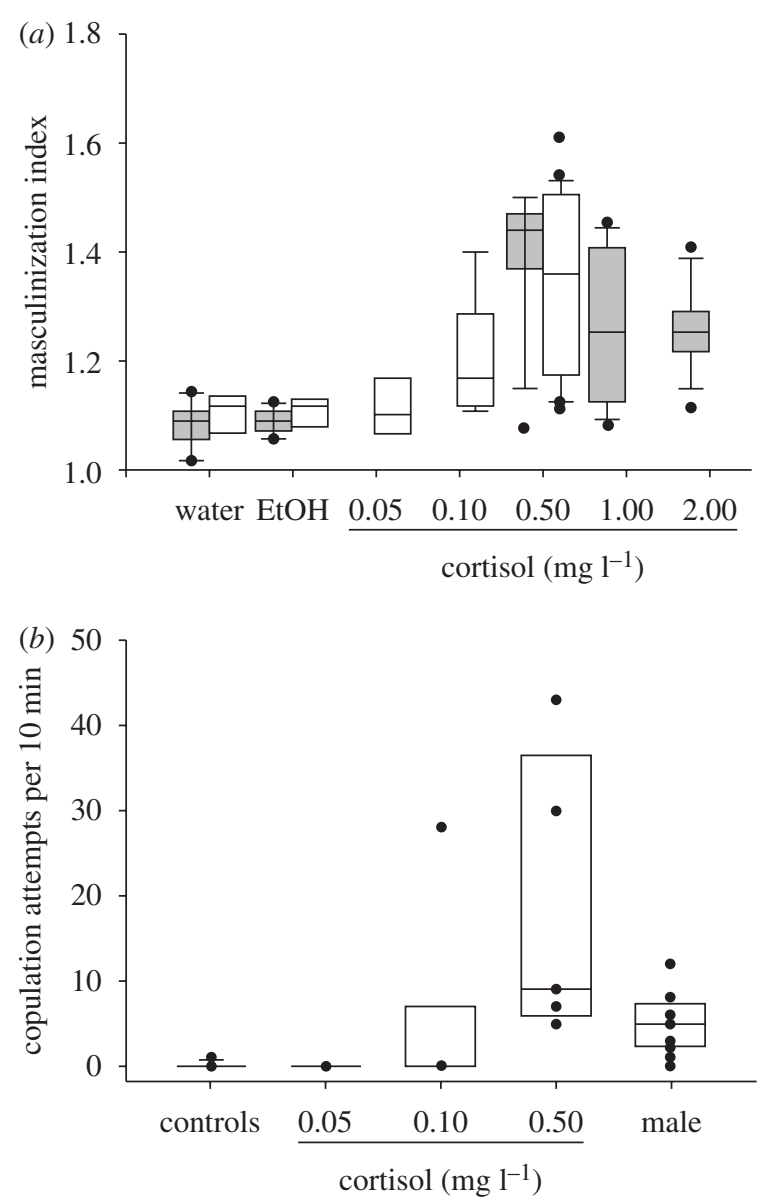

Figure 2. Variation in masculinization of adult female mosquitofish with cortisol concentration. (a) Masculinization index among cortisol treatments and controls over two experiments $(n=5-25)$. Grey bars, experiment 1 ; white bars, experiment 2. (b) Copulation attempts by control and cortisol-treated females $(n=5-12)$ and normal males $(n=8)$. Male copulation attempts are towards control females exposed to water only.

treatment (eight water; five $\mathrm{EtOH}$ ) or to the lower dose cortisol treatments $\left(0.05 \mathrm{mg} \mathrm{l}^{-1}: n=6 ; 0.10 \mathrm{mg} \mathrm{l}^{-1}\right.$ : $n=9$ ) did so.

Distal tip structures (figure 1e) were examined in 33 masculinized females from both experiments (chosen because the anal fin tip was intact). Number of serrae varied from three to eight, and was positively correlated with MI $(r=0.46, n=33, p=0.007)$. Dorsal hooks on rays 4 and 5 always occurred together and were present in all but three females. The ventral blade on ray 4 and spines on ray 3 were difficult to discern and presence was highly variable. There appeared to be no relationship between the presence of either blades or spines with MI or with each other.

In the behaviour trials, evidence of masculinized behaviour varied significantly among treatments (figure $2 b$; electronic supplementary material, video S2; $n=28, \chi^{2}=18.94$, d.f. $\left.=3, p<0.0001\right)$. All females examined from the $0.5 \mathrm{mg}^{-1}$ dose attempted copulations with stimulus females. Of those treated with $0.1 \mathrm{mg}^{-1}$ cortisol, only one exhibited masculinized behaviour, but the number of copulation attempts by this female exceeded that of some females treated with $0.5 \mathrm{mg} \mathrm{l}^{-1}$. The frequency of copulatory attempts by masculinized females actually exceeded the frequency of such attempts by normal males towards control females (figure $2 b$ ). 


\section{DISCUSSION}

We were able to induce morphological and behavioural masculinization of adult females, not by manipulating an androgen, but rather by manipulating a stress hormone. Our results suggest an unexpected interaction between stress and androgenic endocrine pathways in adult vertebrates. Although cortisol-exposed females did not exhibit an MI equivalent to that of normal males (range 2.45-2.61; [10]), they did exhibit MIs and distal tip structures remarkably similar to those of female mosquitofish treated with 11-ketotestosterone (11-KT), the primary androgen in males of many fish species: females fed 11-KT in the diet displayed an MI ranging from 1.35 to 1.55 and eight to 10 serrae (normal male range is five to eight [10]).

Our finding that cortisol can masculinize behaviour and morphology in sexually mature females complements recent studies reporting masculinizing effects of exposure to elevated levels of cortisol, its metabolites or social stress early in life on morphology in fish $[11,12]$, and on the physiology and behaviour of female guinea pigs [13]. The mechanism(s) by which cortisol or stress induce such masculinization in adulthood are currently unknown. However, a strong candidate is upregulation

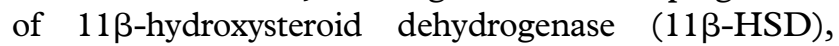
an enzyme that both inactivates cortisol and is involved in synthesis of 11-KT, even in mammals [14].

The distal growth of the rays in cortisol-treated females is additionally surprising because fin rays are bony structures and cortisol typically reduces bone formation, although considerable individual variation in sensitivity exists [15]. Future research will thus be directed at determining the relative roles of cortisol and possible $11 \beta-H S D$-induced androgen production on anal fin elongation.

Our results also have important implications for EDC research. To date, the major focus of effects of EDCs that interfere with glucocorticoid function has been on metabolic syndrome, obesity and immune function [16]. Our findings compel future research efforts to examine possible effects on sexual differentiation of reproductive morphology and behaviour, even for EDCs not traditionally considered to be androgenic or estrogenic, particularly in fishes.

Studies were approved by our institutional IACUC (R08007A, R08-007B).

We thank J. Nguyen, S. Rhodes, N. Franssen, A. Broughton and V. Broughton for fish care, R. Deaton for behavioural expertise, L. Knapp for assistance with figure preparation, R. Riesch for video assistance and four anonymous reviewers for helpful comments on earlier versions of the manuscript. Funding came from the University of Oklahoma's Zoology Department, Sam Noble Oklahoma Museum of Natural History, and Honors College.

1 Sapolsky, R. M., Romero, L. M. \& Munck, A. U. 2000 How do glucocorticoids influence stress responses? Integrating permissive, suppressive, stimulatory, and preparative actions. Endocr. Rev. 21, 55-89. (doi:10. $1210 /$ er.21.1.55)

2 Davis, K. B., Torrance, P., Parker, N. C. \& Suttle, M. A. 1985 Growth, body composition and hepatic tyrosine aminotransferase activity in cortisol-fed channel catfish, Ictalurus punctatus Rafinesque. F. Fish Biol. 27, 177184. (doi:10.1111/j.1095-8649.1985.tb04019.x)

3 Marsh-Matthews, E. \& Deaton, R. 2006 Resources and offspring provisioning: a test of the Trexler-DeAngelis model for matrotrophy evolution. Ecology 87, 3014-3020.

4 Turner, C. L. 1960 The effects of steroid hormones on the development of some secondary sexual characters in cyprinodont fishes. Trans. Am. Microsc. Soc. 79, 320333. (doi: $10.2307 / 3223741$ )

5 Orlando, E. F., Davis, W. P., Edwards, T. M., Sulkowski, D. F., Toft, G. \& Guillette Jr, L. J. 2005 Mosquitofish as sentinels of exposure to environmental androgens and estrogens. In Viviparous fishes (eds M. E. Uribe \& H. J. Grier), pp. 435-453. Homestead, FL: New Life Publications.

6 Gore, A. C. (ed.) 2007 Endocrine-disrupting chemicals: from basic research to clinical practice. Towton, NJ: Humana Press.

7 Nelson, R. J. 2005 An introduction to behavioral endocrinology, 3rd edn. Sunderland, MA: Sinauer Associates.

8 Warner, D. A., Radder, R. S. \& Shine, R. 2009 Corticosterone exposure during embryonic development affects offspring growth and sex ratios in opposing directions in two lizard species with environmental sex determination. Physiol. Biochem. Zool. 82, 363-371. (doi:10.1086/ 588491)

9 Love, O. P., Chin, E. H., Wynne-Edwards, K. E. \& Williams, T. D. 2005 Stress hormones: a link between maternal condition and sex-biased reproductive investment. Am. Nat. 166, 751-766. (doi:10.1086/497440)

10 Angus, R. A., McNatt, H. B., Howell, W. M. \& Peoples, S. D. 2001 Gonopodium development in normal male and 11-ketotesterone-treated female mosquitofish (Gambusia affinis): a quantitative study using computer image analysis. Gen. Comp. Endocrinol. 123, 222-234. (doi:10.1006/gcen.2001.7669)

11 Grillitsch, B., Altmann, D., Schabuss, M., SommerfeldStur, I. \& Moestl, E. 2009 Mammalian steroid stress hormone metabolites masculinize external sex characteristics in fish. Comp. Biochem. Physiol. A 154, S26.

12 Hattori, R. S. et al. 2009 Cortisol-induced masculinization: does thermal stress affect gonadal fate in pejerrey, a teleost fish with temperature-dependent sex determination? PLoS ONE 4, e6548. (doi:10.1371/journal. pone.0006548).

13 Kaiser, S., Kruijver, F. P. M., Swaab, D. F. \& Sachser, N. 2003 Early social stress in female guinea pigs induces masculinization of adult behavior and corresponding changes in brain and neuroendocrine function. Behav. Brain Res. 144, 199-210. (doi:10.1016/S0166-4328(03) 00077-9)

14 Yazawa, T., Uesaka, M., Inaoka, Y., Mizutani, T., Sekiguchi, T., Kajitani, T., Kitano, T., Umezawa, A. \& Miyamoto, K. 2008 Cyp $11 \mathrm{~b} 1$ is induced in the murine gonad by luteinizing hormone/human chorionic gonadotropin and involved in the production of 11ketotestosterone, a major fish androgen: conservation and evolution of the androgen metabolic pathway. Endocrinology 149, 1786-1792. (doi:10.1210/en.2007-1015)

15 Mazziotti, G., Angeli, A., Bilezikian, J. P., Canalis, E. \& Giustina, A. 2006 Glucocorticoid-induced osteoporosis: an update. Trends Endocrinol. Metab. 17, 144-149. (doi:10.1016/j.tem.2006.03.009)

16 Odermatt, A., Gumy, C., Atanasov, A. G. \& Dzyajanchuk, A. A. 2006 Disruption of glucocorticoid action by environmental chemicals: potential mechanisms and relevance. F. Steroid Biochem. Mol. Biol. 102, 222-231. (doi:10.1016/j.jsbmb.2006.09.010) 